\title{
O Ensino Remoto como estratégia deIntervenção Pedagógica em Tempos de Crise Sanitária
}

\author{
Francisco Jose Carvalho Costa - UESPI- franciscojoseatdl3@gmail.com- \\ https://orcid.org/0000-0002-4497-5892 \\ Mikaella de cerqueira soares- UFDPar-mikaellacs@ hotmail.com - https://orcid.org/ \\ 0000-0002-9041-4367 \\ Ana amabile Grabielle Rodrigues Leite -UFPI- anaamabilegabrielle @ gmail.com- \\ https://orcid.org/0000-0003-1157-5312
}

\begin{abstract}
Resumo. A presente pesquisa versa sobre como tem sido o trabalho dos profissionais da Educação Básica de escolas das redes pública e privada de seis estados brasileiros, durante o período de isolamento social ocasionado pela pandemia do novo coronavírus (Sars-Cov-2). Adotadas em sua totalidade de maneira remota, as atividades pedagógicas tiveram sua continuidade baseada em readaptação de modelos de ensino para os Ambientes Virtuais de Aprendizagem bem como a adoção do envio de atividades, em diferentes modalidades. No desempenhar deste trabalho, foram observados fatores que podem influenciar na efetividade do trabalho docente, situações sobre o engajamento dos alunos e dificuldades por parte dos professores no uso de tecnologias bem como a necessidade de formação continuada.

Palavras-chave: educação básica, formação continuada, isolamento social, pandemia, tecnologia.
\end{abstract}

\section{Remote Teaching as a Pedagogical Intervention Strategy in Times of Health Crisis}

Abstract.This paper deals with the work of basic education professionals from public and private schools in six Brazilian states, during the period of social isolation caused by the new coronavirus pandemic (Sars-Cov-2). Adopted in their entirety remotely, pedagogical activities continued based on the re-adaptation of teaching models for Virtual Learning Environments as well as the adoption of sending activities, in different modalities. In carrying out this work, factors were observed that can influence the effectiveness of teaching work, situations on student engagement and difficulties on the part of teachers in the use of Technologies even as the need for continuing education.

Key words: basic education, continuing education,pandemic, social isolation, technologies,

\section{Introdução}

A crise sanitária mundial decorrente da pandemia do novo coronavírus (Sars-Cov-2) desestabilizou a rotina de importantes segmentos sociais e impulsionou a tomada de planos contingenciais para cancelamento ou adiamento de atividades presenciais. A escola, espaço de interação e convivência, passou a ser um espaço virtual em tempo integral e, apesar da constante integração tecnológica nesses espaços, gestores escolares se viram imersos numa realidade de readequação do calendário antes preparado para o modelo de ensino presencial.

No atual contexto, a escola caracteriza-se, enquanto espaço físico, como crítico devido ao risco de transmissão viral. Assim, coube às instituições de ensino básico adaptar seus modelos metodológicos presenciais para os Ambientes Virtuais de Aprendizagem (AVA), tornando as tecnologias as principais referências potencializadoras de iniciativas voltadas para a manutenção da conexão educacional (ARRUDA, 2020).

Os AVA possibilitam que os conteúdos das aulas sejam transmitidos aos alunos através de vários recursos e ferramentas que variam de acordo com as necessidades da proposta oferecida, atendem a necessidade tanto de sistemas educacionais a distância quanto de presencias como suporte as atividades de sala de aula, além disso, possui comocaracterística relevante a possibilidade de ser adquirido gratuitamente, o que torna os AVAs uma Tecnologia Digital de Rede (TDR) acessível para escolas tanto da rede pública de ensino quanto para rede privada (ARAUJO; MERINO; TRISKA, 2018).

A urgência de todos se adequarem às Tecnologias Digitais de Informação e Comunicação (TDIC) é uma situação que considerada inédita desta geração do século XXI, 
criou oportunidades para quem estava acostumado a lidar com as TDIC como uma opção instigou os que não tinham o costume a se apropriarem dos recursos tecnológicos de alguma forma (CANI; SANDRINI; SOARES; SCALZER, 2020).

Nesse constante, o desafio fundamental da educação brasileira tem sido a readequação do cenário para que os estudantes não sejam prejudicados com a pandemia (PEREIRA; NARDUCHI; MIRANDA, 2020), visto que a suspensão das atividades presenciais direcionou os professores e estudantes a realidade online, transferindo e transpondo metodologias e práticas pedagógicas típicas dos territórios físicos de aprendizagem, para um ensino remoto de emergência (MOREIRA; HENRIQUES; BARROS, 2020).

No entanto, frente ao processo de organização do calendário para um modelo de ensino virtual, os profissionais da educação vivenciam impasses evidenciados pelo pouco domínio na usabilidade de tecnologias digitais. Interpreta-se tal problema como desigualdades digitais, que engloba as dificuldades produzidas pela falta de poder aquisitivo na obtenção de aparelhagem tecnológica, falhas na acessibilidade, como baixa largura de banda, a exemplo, e a falta de letramento digital por parte de professores e alunos. Contudo, as dificuldades correntes no eixo social, não tendem a invalidar a potencialidade que a tecnologia digital tem na mediação da construção do conhecimento. $\mathrm{O}$ Planejamento Estratégico do período de 2020 a 2023, desdobramento estratégico de diretrizes para a educação dos anos que se seguem estabelecido pelo Ministério da Educação, define como objetivo estratégico a promoção da "qualificação de professores e demais profissionais da educação, a universalização do acesso à internet e o uso pedagógico de tecnologias digitais". Essa perspectiva objetiva garantir a qualidade da Educação Básica para promoção do acesso, permanência e aprendizagem com equidade. (BRASIL, 2020).

Percebe-se nesse planejamento a importância do letramento digital por parte de professores e do acesso facilitado a internet, para uma construção mais significativa do conhecimento, nos ambientes virtuais. No entanto, o que se pretende alcançar ainda não condiz com a realidade presente neste período de readequação quando o assunto é permanência e aprendizagem com equidade, mas, apesar dos desafios e questões trazidos à tona pela modalidade ensino remoto para a Educação Básica, a paralisação das atividades não é uma opção para muitas realidades do cenário educacional brasileiro (SARAIVA; TRAVERSINI; LOCKMANN, 2020).

Nessa conjuntura, esta pesquisa nasce da problemática de como o comportamento pedagógico em ambientes virtuais e adaptações de modelos metodológicos podem atuar como intervenção de déficits de ensino em tempos de crise sanitária. Tendo como objetivo compreender quais as dificuldades e potencialidades envolvidas nas modalidades de ensino, a saber: aula síncrona, aula online (videoaula) e o envio de atividades impressas ou por redes de comunicação direta (OLIVEIRA e SANTOS, 2020) abordando um diálogo sobre o uso das TDRs mais utilizadas e dialogar sobre quais estratégias melhor se adequam ao cenário atual de acordo com cada contexto.

\section{Percurso Metodológico}

Esta pesquisa foi construída sob o olhar dialógico da tessitura histórico-cultural no âmbito da configuração quantitativa-qualitativa, apoiada em pesquisa de opinião sobre o cotidiano pedagógico das escolas de coordenadores pedagógicos e diretores de diferentes escolas da rede pública e privada de atuação. Participaram da pesquisa 43 coordenadores e diretores da Educação Básica que atuam na Educação Infantil, Ensino Fundamental (Anos Iniciais e Finais) e Ensino Médio de seis estados brasileiros, são eles: Acre (1), Bahia (2), Ceará (7), Distrito Federal (5), Maranhão (13), Minas Gerais (6), Pará, Piauí (7) e São Paulo (1).

2- Levando em consideração que a continuidade das aulas, na modalidade remota, foi 
baseada na tomada de planos contingenciais, por parte da gestão escolar, este é o motivo que levou a presente pesquisa a ter como respondentes coordenadores e gestores pedagógicos. Tal amostra levanta a ideia de uma análise sob um ponto de vista mais holístico da realidade das escolar em tempos de crise sanitária.

De forma a entender como tem sido o trabalho em plataformas virtuais, para aqueles que estão em continuidade do calendário letivo, aplicou-se um questionário sobre como tem sido o manejo dos AVAs e quais as dificuldades envolvidas na usabilidade dos ambientes virtuais utilizados pela escola e, também, como tem sido o trabalho com alunos que não tem acesso facilitado à internet. $\mathrm{O}$ formulário foi disponibilizado via Google Forms $®$, plataforma para construção e veiculação de formulários online, este ficou disponível por 25 dias e foi divulgado em redes sociais.

Para discussão e análise de dados, utilizou-se do conceito de Materialismo Histórico Dialético (MDH), “ [...] o MHD diz respeito à análise dos fenômenos sociais e de seu processo histórico de construção na totalidade em que está inserido" (COSTA; SOUZA; THEREZA JR, 2019).

Neste sentido, o MDH apoia a construção de uma projeção das diferentes realidades presentes na pesquisa, baseando-se nas contradições existentes tais realidades. Entendo que tal cenário apresenta frequentes oposições e que elas modelam a realidade educacional emergente da utilização da tecnologia e evidenciam novas conjecturaspedagógica.

O MDH caracteriza a interpretação e a análise dos resultados, tendo em vista, a exemplo, as diferentes dinâmicas de acesso à tecnologia digital por parte de alunos de escola pública em comparação aos de escola privada.

\section{Resultados e discussões}

Para compreender como a vivência de profissionais da educação nos ambientes virtuais e as adaptações de modelos metodológicos podem intervir pedagogicamente em tempos de crise sanitária, foram analisadas as respostas de 43 coordenadores e diretores atuantes em escolas da rede pública e privada, onde $82 \%$ desses profissionais atuam em escolas da rede privada situadas na zona urbana de seis estados brasileiros e 58,13\% dos participantes dessa pesquisa são da Região Nordeste.

$\mathrm{Na}$ conjuntura em que se abrange e delimitam os "fins" (os "porquês") e "meios" (o "como") a tecnologia age de forma a remediar os problemas sociais em suas possibilidades históricas (MALAGGI, 2020). Assim, sob o ponto de vista material, a tecnologia engendra o potencial para a continuidade das aulas no período de crise, o que sob a ótica histórico filosófica se entende "[...] como instrumentalidade que se presta a todo propósito e finalidade [...]" e (MARCUSE, 2015, p. 162).

Quando questionados sobre a continuidade das atividades durante o período decorrente da crise sanitária, 90,7\% dos participantes evidenciaram que as escolas em que atuam adequaram-se ao ensino remoto durante a pandemia e continuam em atividade. De 43 coordenadores e diretores pedagógicos apenas 4 apontaram a não continuidade das aulas, ao analisar tais respostas, foi observado que os participantes atuam em escolas na área da Educação Infantil.

Retomando a discussão em (MARCUSE, 2015), na atualidade somente os meios (o "como") tem sido discutidos, e neste sentido, "são técnicos; a racionalidade que lhe dá sentido, ao abordar o real"(MALAGGI, 2020) e, nesta perspectiva histórica sobre a realidade humana é que se observa um grande revés: a sintetização de uma forma clara de submissão racionalizada dos indivíduos a suas próprias criações agregando a elas uma configuração messiânica em sentido tecnológico. (MALAGGI, 2020). 
Em um apanhado geral, no levantamento de dados da presente pesquisa, 51,2\% dos envolvidos relatam que a continuidade das atividades pedagógicas se deu via modalidade síncrona de aulas, além disso, 20,9\% das respostas evidenciam o trabalho com videoaulas gravadas e disponibilizadas em plataformas online, outros $23,2 \%$ no envio de atividades e 4,7\% ainda não adotaram modelos de aulas remotas.

Apesar das potencialidades das TDRs no processo de ensino aprendizagem, é relevante conhecer qual a opinião dos profissionais sobre o trabalho nas plataformas virtuais, neste sentido, ao serem indagados sobre a efetividade do trabalho nas plataformas de ensino, $78,6 \%$ consideram o trabalho eficaz. Dentre os modelos de aulas adotados, destaca-se a aula síncrona com $86,95 \%$ de avaliações positivas sobre sua efetividade, quanto ao envio de atividades impressas, há menor adesão entre os participantes da pesquisa, apresentando $40 \%$ de opiniões favoráveis à sua efetividade.

A quantidade média de alunos da presente pesquisa por escola é de 100 a 200 alunos. Ao ser analisada a respondência à seguinte pergunta "existem alunos que não estão acessando as aulas virtuais?", obteve-se a informação que em $74 \%$ das unidades existem alunos que não são assistidos pelos modelos de aulas adotados nas escolas, o que nos leva a refletir que a modalidade de ensino remoto virtual ocasiona desigualdades no que concerne à equidade do ensino.

Nesta tessitura, o fenômeno tecnológico não pode ser interpretado como um fator isolado, ou seja, se configura como um processo social desde seu âmago, configurado pelas relações entre os seres humanos em determinadas situações históricas a partir de suas necessidades existenciais (MALAGGI, 2020). Seguindo a discussão, os modelos metodológicos adotados podem, a partir do caráter sociodemográfico, gerar desencontros, dos quais pode-se citar a evasão por inacessibilidade ocasionada por fatores externos à instituição.

Uma análise realizada no Estado do Rio Grande do Sul a partir da necessidade de adaptação para atividades remotas constatou que a migração das atividades escolares vem manter ou até aprofundar os processos de exclusão, seja de acesso à rede, seja de condição de realização das atividades nas casas dos estudantes e até de sobrevivência, como alimentação (SARAIVA; TRAVERSINI; LOCKMANN, 2020).

Para atender aos alunos que não têm acesso às aulas síncronas ou gravadas, os professores adotaram como alternativa o envio de atividades via redes de comunicação direta, como WhatsApp e ligação - telefônica - de acompanhamento, como descrito pelos participantes. A adoção de planos contingenciais foi uma das estratégias para a continuidade das atividades na Educação Básica e adequação de realidades em diferentes contextos diferentes para garantir o acesso à educação, onde $90 \%$ dos coordenadores e diretores evidenciaram a tomada de plano contingencial para o calendário letivo durante o período de pandemia.

Mesmo com o elevado percentual de escolas que estão dando continuidade às atividades durante o período de pandemia, 52,4\% dos participantes afirmaram que em sua escola não houve capacitação sobre como manusear as ferramentas tecnológicas e, $48 \%$ ainda estão aprendendo a usar os AVAs e plataformas digitais. Neste intento, foi pertinente entender quais as dificuldades envolvidas no processo de não capacitação, paraisso, usaram-se do contexto dialógico, e os professores relataram que:

"Interfere na qualidade das aulas, por vezes o professor fica inseguro e ou perde muito tempo buscando e tentando aprender sozinho" (Coordenador Pedagógico 17).

“Os professores tiveram acesso aos tutoriais e muitos nos surpreendem com o domínio da ferramenta. No entanto, a não capacitação traz insegurança e medo à equipe" (Coordenador Pedagógico 12). 
"O de sentir nos professores a dificuldade de usar as ferramentas tecnológicas, porém se percebe que houve mudanças, estão se adequando aos poucos" (Coordenador Pedagógico 30).

Mesmo com a importância do uso de TDRs para veiculação das atividades formativas durante a pandemia, é notória a falta de domínio das técnicas envolvidas no uso de aparatos digitais pelos professores. Neste intento, presencia-se a alienação dos indivíduos, daquilo que por eles foi criado, partindo da dissociação entre técnica e tecnologia, onde se apresenta um cenário, tangido pelas disparidades entre o uso de tecnologias e a necessidade de domínio de técnicas, pertinente de construção cognitiva nautilização das TDRs.

"Foi difícil no início, mas juntos, fomos aprendendo e hoje já está mais tranquilo" (Coordenador Pedagógico 9).

"Muito estresse para o professor, angústia, preocupação e acima de tudo uma busca para aprender e se envolver. Foi muito difícil” (Coordenador Pedagógico25).

De acordo com os dados desta pesquisa, $48 \%$ dos professores estão aprendendo a usar tecnologias que auxiliem no ensino remoto, ainda, evidencia-se que $61 \%$ dos professores não possuem TDRs à sua disposição na escola em que trabalham. Nenhum dos profissionais declarou não saber usar o AVA para ministrar aulas, o que pode nos apresentar um cenário de adaptação por parte dos professores.

Tendo em vista que a educação nos ambientes digitais necessita de alta conectividade, além de velocidade e fluidez, é preciso desenvolver processos de formação que possa integrar os professores ao universo das tecnologias digitais (SARAIVA, 2020). Potencializar a formação de professores mostra-se desafiador, face as rápidas mudanças de cenário, no entanto, isso pode auxiliar na promoção de novas propostas de ensino- aprendizagem.

As escolas devem orientar seus professores a reinventarem estratégias de ensino, nesse período pandêmico, a maior parte da responsabilidade em lidar com essa questão foi delegada aos docentes de modo individualizado, essa responsabilização dos professores tende a fortalecer a intensificação do trabalho. Há um difícil equilíbrio entre continuar as atividades letivas e administrar o momento atual, que tem gerado estresse e ansiedade para o corpo docente (SARAIVA; TRAVERSINI; LOCKMANN, 2020).

Tendo em vista que o acesso às redes digitais facilita a comunicação durante o período pandêmico, observou-se que 76,92\% das escolas que não possuem internet à disposição dos docentes são da rede pública de ensino, onde 53,84 \% encontram-se localizadas na região Nordeste, $38,46 \%$ no Sudeste e 7,7\% no Norte do país. Em relação ao percentual de escolas que possui internet, $69,8 \%$ dos participantes declaram que as escolas em que trabalham disponibilizam internet aos professores, entretanto apenas $26,66 \%$ deste percentual é de escolas públicas, o que configura menor acesso à internet no ambiente de trabalho por professores da rede desse seguimento.

Outra preocupação abarcada pela pesquisa na realidade das aulas virtuais é o engajamento dos alunos. Ao se inserir no contexto dos ambientes virtuais, sejam de aprendizagem ou de comunicação síncrona, é pertinente remodelar metodologias e modelos de ensino para a nova realidade, levando em consideração as necessidades dos profissionais, no ambiente das TDRs, e seus objetivos.

Para conhecer melhor tal realidade, organizou-se uma projeção das observações dos profissionais acerca do engajamento alunos tendo como base os descritores: ótimo 2,5\%, bom $57,5 \%$, regular 37,5\%, ruim 2,5\%. Questões comportamentais, emocionais e cognitivas, mostram-se diretamente ligadas ao nível de engajamento dos alunos, levando em consideração que o envolvimento do aluno com as atividades trabalhadas é essencial para o resultado efetivo no processo de ensino-aprendizagem (NOVAES, 2018). 
Para os profissionais participantes, a situação socioeconômica dos alunos influencia diretamente no acesso às TDRs, ocasionando problemas relacionados ao baixo engajamento dos alunos nas aulas em plataformas, uma vez que existem estudantes que não possuem material tecnológico. Além da intervenção profissional, abaixo, foram listados relatos discursivos que podem atuar como soluções para o baixo engajamento.

"No atual contexto, as aulas são a única forma de interação entre professores ealunos, mas alguns alunos não conseguem acesso e não conseguem acompanhar as aulas, seja por motivos de não ter um aparelho que lhe permita o acesso ou por não conseguir ajuda, por se tratar de uma criança pequena, necessita de ajuda e por morar com os avós, os quais não conseguem entender como funciona, mesmo nos disponibilizando para ajudar, a pessoa idosa tem dificuldade e consequentemente a criança fica sem assistir as aulas online" (Coordenador Pedagógico 11)

“O que sabemos é que muitos não têm acesso, pelas suas condições materiais, tipo um celular por família, não possuem computadores, notebook e principalmente lhes faltam a INTERNET. Sugestão ao governo municipal- acesso à internet gratuita para esses fins educacionais. "(Coordenador Pedagógico 15).

"O acesso a computadores e outras ferramentas online, além do celular"

"Primeira que parte deles não tem acesso, o poder público poderia já ter adotados redes gratuitas de internet e disponibilizado nas comunidades. Grupos de apoio (videoconferências com psicólogo, psicoterapeuta, assistente social, nutricionista) para interação visando criação de vínculo com famílias. Por fim depois de ter a certeza que todos têm acesso, e do acolhimento, realizar debates que levem as famílias a refletirem acerca da importância do estudo para os filhos e sociedade." (Coordenador Pedagógico 09). "Inicialmente nossas aulas eram apenas gravadas e enviadas em plataformas digitais
com o auxílio de tarefas impressas e digitais, porém o engajamento era pouco, então
passamos a integrar também as aulas ao vivo e aliar com os outros recursos foi o que
melhorou o engajamento das crianças e das famílias, passamos a ter um resultado
melhor." (Coordenador Pedagógico 16).

"Na verdade, as maiores dificuldades são causadas pelas dificuldades técnicas dos alunos. Por essa razão, a equipe de TI da escola é fundamental nesse projeto para a

orientação dos alunos diante de qualquer dificuldade. " (Coordenador Pedagógico 18).

Participação familiar e aparatos tecnológicos que possibilitem acesso às redes, mostram-se como importantes aspectos na realidade educacional advinda da crise sanitária. Todavia, é relevante conhecer a opinião dos envolvidos no processo ensinar- aprender, mediado pelos ambientes virtuais.

Como observado no presente texto, as aulas remotas se configuram como a adaptação de modelos pedagógicos para sua continuidade em ambientes virtuais, partindo desta análise, entende-se a necessidade de integração de materiais tecnológicos que auxiliem na produção ou veiculação das aulas remotas. Com base em lavamento bibliográfico, está organizado no Quadro 1, uma classificação de aparelhos tecnológicos de acordo com as tipificações com TDR e TDIC.

O trabalho com as TDRs, apresenta uma realidade onde as tecnologias se configuram como uma linguagem para além de objetos eletrônicos, tal linguagem, conecta os indivíduos com a multiplicidade do ciberespaço (MALAGGI, 2018). As arquiteturas multimidias das redes, em sua potencialidade hipertextuais, insere no cotidiano escolar a combinação de imagem, escrita, sons, assim como estruturas audiovisuais (SANTAELLA, 2013).

Tal categorização se explica pela necessidade de entender que as TDRs representam uma linguagem particular do ciberespaço (MALAGGI, 2018), com isso, pode-se entender as 
TDRs como instrumentos importantes para a construção de uma inteligência de forma coletiva.

Quadro 1. Categorização de aparatos tecnológicos digitais

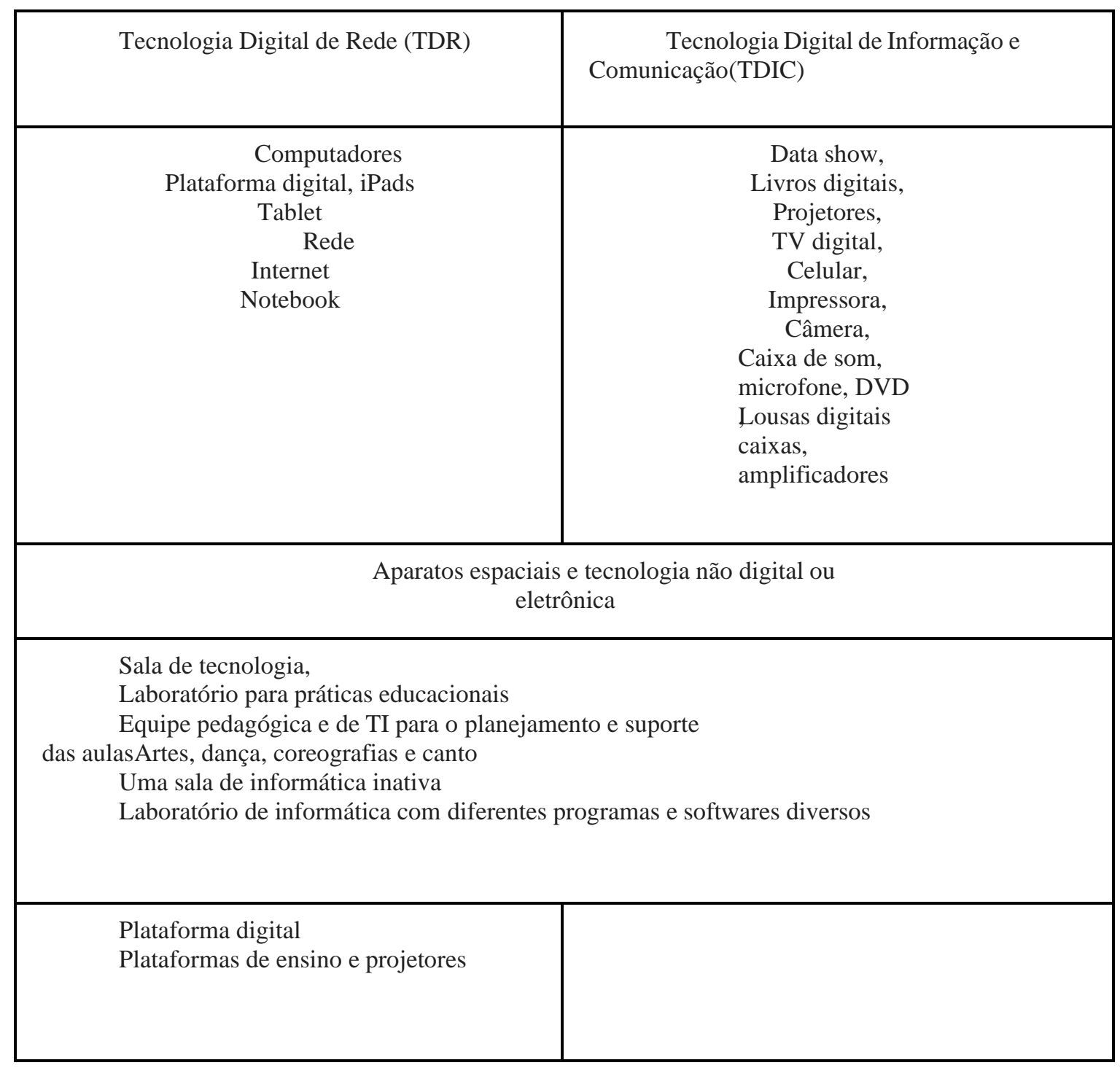

Fonte: Malaggi, 2018

Quando questionados sobre o que poderia ajudar a melhorar o desenvolvimento dos professores na criação e produção de aulas remotas, 35\% dos participantes responderam a necessidade de uma internet com boa qualidade e conexão rápida, 50\% afirmaram a necessidade de haver mais capacitação para uma formação especializada, com enfoque em treinamento técnico e pedagógico, ou seja, a formação continuada dos professores para uso das TDRs e TDICs, e 20\% recobraram a necessidade de plataformas mais interativas com ação e reação dos alunos, outros $10 \%$ ressaltaram a necessidade de condições físicas de trabalho adequadas para o ensino remoto, que reitera-se no relato a seguir:

“Hoje, estamos trabalhando no sistema Home office e as nossas residências não são o ambiente mais propício para a realização desse processo pelas interferências naturais. Somando-se a isso temos os recursos tecnológicos, as falhas da internet e o fato dos professores serem movidos pela necessidade de estar com os alunos. Muitos precisam de exemplos e treinamento para melhorar a qualidade das aulas. Esse apoio 
os professores da minha escola possuem" (Coordenador Pedagógico, 28)

“Os professores estão dando show nas aulas remotas, porém infelizmente a maioria dos alunos não tem tido acesso a essas aulas, por diversos motivos, como falta de aparelhos tecnológicos, internet e um bom acompanhamento familiar, por mais que as famílias tentam, não substitui o contato presencial do professor x aluno" (Coordenador Pedagógico, 31)

Os questionamentos nesse momento pandêmico conduz a reflexão não somente sobre $\mathrm{o}$ acesso às tecnologias, mas, da possibilidade de serem ofertadas a professores e alunos condições para uso pleno dos recursos tecnológicos, de modo a favorecer uma aprendizagem interativa e colaborativa, uma vez que os desafios e os fatores implicados, desde a falta de estrutura tecnológica das escolas, formação dos próprios professores e alunos para um uso crítico das tecnologias são muitos (CANI; SANDRINI; SOARES; SCALZER, 2020).

\section{Considerações Finais}

Essa pesquisa teve como objetivo compreender dificuldades e potencialidades envolvidas nas modalidades de ensino adotadas durante a crise sanitária vivenciada no século XXI analisando as estratégias utilizadas por coordenadores e diretores de escolas da rede pública e privada de seis estados brasileiros.

Os dados obtidos através dos relatos e respondência às questões pontuadas no formulário da pesquisa ressaltam a presença de desigualdades de acesso quando se trata da educação mediada pelos artifícios digitais, além disso, a não formação de professores para o uso de tecnologias educacionais e o pouco contato durante as aulas presenciais, pode impactar diretamente na relação de adaptação de modelos pedagógicos para os ambientes virtuais. Contudo, a mediação pedagógica se mostra como forte aliada na construção da continuidade da educação em meio à crise sanitária.

As tecnologias mostram-se, aqui, como rompimento de barreiras no que tange ao distanciamento físico. A aproximação de alunos e professores, mediada pela tecnologia, pode se dar das mais diversas maneiras, incluindo desde o contato síncrono até a postagem de atividades via redes ou mesmo a tradicional ligação. Entender a relação existente entre professores e as tecnologias é importante no conhecimento dos impactos que ela pode ocasionar na educação de modo geral.

Discutir e entender a realidade de profissionais da educação em tempos de crise evidenciou uma série de disparidades tangidas pelas diferentes realidades envolvidas no ambiente da pesquisa, ter necessidade de usar e mesmo ter à sua disposição tecnologias digitais, não configura domínio de uso. A readaptação de modelos conjecturou um movimento de construção cognitiva sobre as tecnologias entre os profissionais da educação, bem como deixou às claras as desigualdades que as TDRs podem elencar mesmo se mostrando como de importante ajuda na continuidade das aulas.

Percebe-se que mesmo com a evidencia de dificuldades e necessidade de processo de adaptabilidade por parte dos professores, estes, tem manuseado as TDICs e TDRs que estão disponíveis ao seu alcance, seja no espaço físico da escola ou em seus espaços residenciais. No entanto, é inegável, diante dos relatos, a necessidade de capacitações para garantir a formação continuada para os professores com o objetivo de qualificar a ação docente dos professores no uso das tecnologias para engajamento dos alunos. Pois além do suporte técnico quanto ao uso dessas das TDICs, o professor necessita, ainda, do suporte para um uso com fins pedagógicos.

Como potencialidades, observa-se que as escolas de diferentes contextos, apesar de enfrentarem desafios relacionados a conexão de internet, espaços físicos de qualidade e formação para aulas mais interativas, frente a esse período que se apresentou como novo, 
souberam adequar seus contextos para as diferentes realidades dos seus alunos e continuidade das atividades pedagógicas.

\section{Referências}

ARAUJO, G. F. L.; MERINO, E. A. D.; TRISKA, R. Métodos mais usados para avaliações de Ambientes Virtuais de Aprendizagem (AVAs). Human Factors in Design, v. 7, n. 13, p. 132-147, 2018

ARRUDA, E. P. EDUCAÇÃO REMOTA EMERGENCIAL: elementos para políticas públicas na educação brasileira em tempos de Covid-19. EmRede-Revista de Educação a Distância, v. 7, n. 1, p. 257-275, 2020.

BRASIL. Ministério da Educação. Plano Estratégico. Plano Estratégico Institucional 20202023. Brasília, 2020, 60p. Disponível em:

http://portal.mec.gov.br/index.php?option=com_docman\&view=download\&alias=1455 91plano-estrategico-mec\&category_slug=maio-2020-pdf\&Itemid=30192. Acesso em: 09 de jul. 2020.

CANI, Josiane Brunetti. Educação e covid-19: a arte de reinventar a escola mediando a aprendizagem "prioritariamente" pelas TDIC. Revista Ifes Ciência, v. 6, n. 1, p. 23-39, 2020.

COSTA, R. L.; SOUZA, M. A. R.; THEREZA JR, A. H. Materialismo Histórico- Dialético e pesquisas em Informática na Educação. Metodologia de pesquisa científicaem Informática na Educação: abordagem qualitativa, SBC. Disponível em: https://metodologia.ceiebr.org/wp-content/uploads/2018/10/livro3_cap5_MHD.pdf, 2020. Acesso em: 29 de jun. 2020 .

MALAGGI, V.; DA SILVA, J. T.; TEIXEIRA, A. C. "O senhor me ouve, pensa e repensa, e rediz, então me ajuda": notas freirianas sobre a relação educador-educandono ensinoaprendizagem on-line. Revista Linhas, v. 19, n. 41, p. 182-212, 2018.

MALAGGI, Vitor. TECNOLOGIA EM TEMPOS DE PANDEMIA: A EDUCAÇÃO A DISTÂNCIA ENQUANTO PANACEIA TECNOLÓGICA NA EDUCAÇÃO BÁSICA. Criar Educação, v. 9, n. 2, p.51-79, 2020.

MARCUSE, H. O homem unidimensional: estudos da ideologia da sociedade industrial avançada (R. Oliveira, DC Antunes, \& RC Silva, trads.). São Paulo, SP: Edipro.(Trabalho original publicado em 1964), 2015.

MOREIRA, J. António; HENRIQUES, Susana; BARROS, Daniela Melaré Vieira. Transitando de um ensino remoto emergencial para uma educação digital em rede, em tempos de pandemia. Dialogia, p. 351-364, 2020.

NOVAES, I. C. Internet das coisas na esfera educacional: aplicação e seus desafios. In: Congresso Transformação Digital 2018. 2018.

OLIVEIRA, F. A.; DOS SANTOS, A. M. S. Construção do Conhecimento na Modalidade de Educação a Distância: Descortinando as Potencialidades da EaD noBrasil. EaD em Foco, v. 10, n. 1, p. 26-26, 2020. https://doi.org/10.18264/eadf.v10i1.799

PEREIRA, Alexandre de Jesus; NARDUCHI, Fábio; DE MIRANDA, Maria Geralda. V. $19 \mathrm{~N}^{\circ}$ 2, Dezembro, 2021 DOI: https://doi.org/10.22456/1679-1916.121182 RENOTE 
Biopolítica e Educação: os impactos da pandemia do covid-19 nas escolas públicas. Revista Augustus, v. 25, n. 51, p. 219-236, 2020.

SANTAELLA, L. Comunicação ubíqua: repercussões na cultura e na educação. Pia Sociedade de São Paulo-Editora Paulus, 2013.

SARAIVA, K.; TRAVERSINI, C.; LOCKMANN, C. K. A educação em tempos de COVID19: ensino remoto e exaustão docente. Práxis Educativa, Ponta Grossa, v. 15,e2016289, p. 124, 2020. https://doi.org/10.5212/PraxEduc.v.15.16289.094 